\title{
Visual form perception is a function of the visual cortex: II. The rotated horizontal-vertical and oblique-stripes pattern problems
}

\author{
DAVID G. LAVOND and ROBERT G. DEWBERRY \\ Laboratory of Comparative \& Physiological Psychology, Ohio State University, Columbus, Ohio 43212
}

\begin{abstract}
Rats prepared with serial visual-cortical ablations and interoperative relearning easily relearn a mirror-image problem presented by the rotation of horizontal-vertical stimuli by $45 \mathrm{deg}$ (turning it into an oblique-stripes problem on diamond-shaped doors), although the problem was initially very difficult to learn. Similarly treated rats trained on an obliquestripes problem that has also been rotated by $45 \mathrm{deg}$ (turning it into a horizontal-vertical stripes problem on diamond-shaped doors) cannot relearn the problem although originally they had learned the problem very easily. The results are discussed in terms of the orientation and local flux-contour cues that exist in the horizontal-vertical and oblique-stripes pattern problems as well as in other tests of visual pattern and form perception. It is concluded that visual form perception is a function of the visual cortex.
\end{abstract}

Horel, Bettinger, Royce, and Meyer (1966) reported that rats prepared with simultaneous bilateral posterior decortication cannot learn to discriminate between arrays of obliquely-oriented stripes (stripes oriented at 45 and $135 \mathrm{deg})$. The findings were subsequently confirmed when Jonason, Lauber, Robbins, Meyer, and Meyer (1970) found that posteriorly decorticated rats treated with amphetamine, a treatment that augments black-white relearning, still cannot discriminate the $O B$ problem. Thus, the results of both studies supported the conclusion of Lashley (1939) that visual neocortex is necessary for visual pattern and form discrimination.

The conclusion of Lashley was challenged when Spear and Barbas (1975) found that rats prepared with serial bilateral ablations of the posterior cortex and with interoperative retraining can readily relearn a horizontal-vertical stripes discrimination problem. Furthermore, they reported that two of three rats from a control group with simultaneous bilateral posterior decortication relearned the HV problem after more than 800 trials of relearning. As a result, Spear and Barbas concluded that the inability of the subjects in the Horel et al. experiment to relearn the oblique-stripes problem was due to the fact that Horel et al. had limited the number of retraining trials to 300 .

Lavond, Hata, Gray, Geckler, Meyer, and Meyer (1978) subsequently compared the performances of

This research was supported, in part, by Grant MH-06211 from the National Institute of Mental Health to Donald R. Meyer and Patricia M. Meyer. This research was presented by the first author as partial fulfillment for the degree of doctor of philosophy while holding a university fellowship. The second author was a first-year university fellow. Address reprint requests to the first author, who is a temporary lecturer at the Department of Psychology, University of California, Riverside, California 92521. serially operated rats with extensive retraining which were tested in either the horizontal-vertical problem (HV problem) or the oblique-stripes problem (OB problem) and given extensive final retraining. Lavond et al. confirmed the findings of Spear and Barbas (1975) that rats prepared with serial posterior lesions and given interoperative retraining eventually relearned the HV problem in about 300 trials. However, similarly prepared rats could not relearn the OB problem in 850 trials, which was 15 to 16 times the number of trials needed to learn the problem.

Lavond et al. (1978) proposed that the HV problem was not a rigorous test of form perception because it could be solved on the basis of local flux or local contour cues. Thus, a rat that adopts the strategy of examining the bottom edge of the two stimulus doors will find that the bottom edge of the vertically striped door is broken by black and white stripes, but that the bottom edge of the horizontally striped door is a solid black or white stripe alone. A similar strategy with the OB problem is fruitless because all of the edges of both stimulus doors are broken by black and white stripes. The OB problem must be solved by discriminaton of the orientations of the stripes, and Lavond et al. found that posteriorly decorticated rats could not make this discrimination. Therefore, they concluded that Horel et al. (1966) were correct in interpreting their findings as supportive of the concept of Lashley (1939) that visual form perception is cortically dependent.

Unfortunately, the OB problem is more difficult for normal rats to learn than the HV problem. Thus, it could be argued that posteriorly decorticated rats still perceive differences in orientations of stripes but that other stimulus features of the $O B$ problem inhibit that discrimination. For example, the $\mathrm{OB}$ 
problem is a mirror-image problem, and such kinds of tasks are often difficult for normal rats to learn (Lashley, 1938). The obliqueness of the lines per se in the OB problem may also be a factor contributing to its difficulty, because rats are normally raised in carpentered environments of horizontal and vertical lines and have had little experience with lines of other orientations.

The present study was designed to evaluate the criticisms of the use of the OB problem as a test of form perception. Form perception is defined here as the ability to discriminate arrays of lines independently of flux or contour cues (cf. Ritchie, Meyer, \& Meyer, 1976). Rats were prepared with serial cortical ablations and were given interoperative retraining (Thompson, 1960) to discriminate between two new versions of the $\mathrm{OB}$ and $\mathrm{HV}$ stimuli originally used by Lavond et al. (1978). In the new versions, the original stimulus panels were presented in doorways that rotated the stimuli by $45 \mathrm{deg}$. Thus, when the original HV problem was rotated, it became an obliquely oriented stripes task, and the rotation of the OB problem resulted in a discrimination between horizontally and vertically striped arrays.

\section{METHOD}

\section{Subjects}

The subjects for this experiment were 22 male hooded rats between the ages of 90 and 120 days at the beginning of the experiment. The rats were individually housed and maintained on ad-lib food and water. They were randomly assigned to two groups of 11 rats each, which were designated as the rotated $\mathrm{HV}$ and the rotated $\mathrm{OB}$ groups.

\section{Apparatus and Procedure}

The rats were trained in a Thompson-Bryant (1955) two-choice apparatus constructed from black plastic. It was basically the same apparatus as that used in the experiments by Horel et al. (1966) Jonason et al. (1970), Lavond et al. (1978), and Spear and Barbas (1975). The apparatus consisted of a startbox, a choice compartment, and a goalbox. The first two compartments were separated by a small opaque guillotine door. The choice compartment and the goalbox were separated by a wall that contained two diamond-shaped doorways, $9 \times 9 \mathrm{~cm}$ on a side. The doorways were $5 \mathrm{~cm}$ apart and separated by a perpendicular partition that extended $7.5 \mathrm{~cm}$ into the choice compartment. The startbox and choice compartment were illuminated by small overhead fluorescent lamps mounted onto transparent roofs. The floors of the start and choice compartments were made of $3 / 16$ in. stainless steel bars separated every $1 / 2$ in. to form a grid to deliver motivating footshock to the subjects.

The stimuli were the same as those used in the Lavond et al. (1978) experiment. They were patterns on the surfaces of doors that fitted into the two doorways. The discriminanda for the original HV problem consisted of alternating black (with a brightness of $.1 \mathrm{~mL}$ ) and white (with a brightness of $3.0 \mathrm{~mL}$ ) stripes $(2.6 \mathrm{~cm} /$ cycle) which were either vertically or horizontally oriented in the original Lavond et al. experiment. The discriminanda for the original $O B$ problem in the Lavond et al. experiment consisted of alternating black and white stripes $(2.5 \mathrm{~cm} / \mathrm{cycle})$ at an orientation of 45 or $135 \mathrm{deg}$ from horizontal. In the original Lavond et al. experiment, the stimuli had been presented in squareshaped doorways. In the present experiment, the use of the diamond-shaped doorways resulted in the rotation of the original stimuli by $45 \mathrm{deg}$. Thus, the original HV stimuli, when rotated and fitted into diamond-shaped doorways, became a mirror-image problem. The original $O B$ stimuli, when rotated and fitted into diamond-shaped doorways, appeared to be a horizontal-vertical problem.

The rotated HV problem was presented with the same set of four doors used for the original $\mathrm{HV}$ problem. Each door consisted of either four black and three white stripes or three black and four white stripes. On any given trial, a door with a 45-deg orientation with respect to horizontal was paired with one or the other of the doors that had a 135-deg orientation. Hence, four combinations of doors were used. The pairings of the doors were governed by a Gellerman (1933) series, and the left-right positions of the 45- and 135-deg rotated $\mathrm{HV}$ patterns were governed by another such series.

The rotated $O B$ problem was presented with a single pair of doors. There were 10 stripes within each pattern, and the relative positions of the black and white stripes were altered on a trialto-trial basis by rotating the doors $180 \mathrm{deg}$. Thus, although only two doors were used, the doors were paired in four different ways as a means of controlling for solutions of the problem by means of local flux or local contour cues (cf. Ritchie et al., 1976). As in presentations of the rotated HV problem, the variations in pairings of the rotated $O B$ doors and the left-right positions of the two discriminanda were governed by Gellerman series.

Prior to pretraining, each of the rats was handled for at least 5 min per day for a total of 5 days. On Day 6 , each rat was permitted to explore the apparatus for $15 \mathrm{~min}$ while all of the doors were removed. On Day 7, the guillotine door was replaced, and the animals first were trained to avoid shock by running into the goalbox. Next, on that same day, pretraining doors made of thin slats of black plastic were placed into the doorways that led into the goalbox. The rats were pretrained to exit from the choice compartment by knocking down a pretraining door. The incentive was avoidance of shocks to the feet $(.2-.4 \mathrm{~mA})$, set at the minimally effective level for the subjects. The animals were allowed approximately $15 \mathrm{sec}$ after the startbox guillotine door was raised before they received a shock. After entering the choice compartment, an interval of approximately $25 \mathrm{sec}$ was allowed for exit before the rats received the motivating footshock.

On Day 8, preoperative training was begun on either the rotated $\mathrm{HV}$ or the rotated $\mathrm{OB}$ problem using the spaced-trial training method of Glendenning (1972). Each of the subjects was run for 25 trials per day, with rests of 10 to 15 min between the 8th and 9th trials and between the 16th and 17th trials. The incorrect stimulus door was locked at the rear, which required that the subject exit from the choice compartment by knocking over the correct stimulus door. The correct stimulus for the rotated HV problem had the stripes oriented at $135 \mathrm{deg}$ from horizontal (parallel to a line drawn from the upper left to the lower right of the door) because the correct door of the original OB problem in the Lavond et al. (1978) study was also oriented at $135 \mathrm{deg}$. The correct stimulus for the rotated OB problem had the stripes oriented horizontally since the correct door of the original HV problem in the Lavond et al. study was horizontally oriented. An error was defined as a close approach to the negative door, as touching the negative door, as stepping upon any of the first four bars in front of the negative door, or as a hesitation of more than $10 \mathrm{sec}$ immediately in front of the doors without making a choice. The subject was punished with a mild footshock for any of these transgressions. The subjects were trained to a criterion of 9 correct responses in 10 successive trials, and that criterion was typically achieved by the 2 nd day of training on the problem.

\section{Surgical and Retraining Procedures}

On Day 11, after each animal had learned the rotated HV or rotated $\mathrm{OB}$ problem, the first-stage surgical procedures were performed. At that time, each of the rats was subjected to a unilateral radical ablation of the posterior cortex. The size of the 
lesion was intended to extend from bregma to the occipital pole and from the sagittal sinus to the rhinal sulcus. The lesions were produced by pia-stripping and then by aspiration of the margins of the wound (cf. Meyer \& Meyer, 1971). The size of the lesion typically included areas $17,18,18 \mathrm{a}, 7,20,29 \mathrm{c}$, and 40 , as defined by Krieg (1946) for the rat. Thus, the lesion sizes were comparable to the lesions of the subjects of Horel et al. (1966), Jonason et al. (1970), and Lavond et al. (1978) Experiment 1 , and destroyed all the areas which receive a visually significant projection from the nucleus lateralis posterior and/or the dorsal lateral geniculate nucleus in the rat (Hughes, 1977). The surgery was performed with a clean technique while the rat was anesthetized with sodium pentobarbitol. Following surgery, the animals were administered a prophylactic broad-band antibiotic. One rat in the rotated HV group died after surgery.

After 11 days of postoperative recovery, each rat was retrained $\left(R_{1}\right)$ to the criterion of 9 correct responses in 10 consecutive trials on the same visual problem that the subject had learned before surgery. Two weeks following the first surgery, each subject was reoperated upon and the still-intact contralateral posterior cortex was destroyed. The methods were the same as those followed in the first-stage surgery. One rat in the rotated HV group and 1 rat in the rotated $O B$ group died after the second surgery. Another rat in the rotated OB group developed a urinary infection and did not continue the procedures. The remaining 18 rats were once again permitted to recover from surgery for 11 days, and then final relearning $\left(R_{2}\right)$ was begun on Day 35 on the same problem each rat was originally trained and interoperatively retrained $\left(R_{1}\right)$ upon. Each group of rats was retrained on their respective pattern problem for a total of 300 trials $(25$ trials per day for 12 days). Thereafter, all of the rats were trained for original learning of a simple black-white discrimination.

\section{Histological Procedures}

Following the neurobehavioral procedures, the rats were overdosed with sodium pentobarbitol and perfused intracardially with saline, followed by $10 \%$ Formalin. The brains were then removed and stored in Formalin. The extents of the cortical ablations were drawn on standard Lashley diagrams, and then the brains were frozen and sectioned at $30 \mu \mathrm{m}$. Every 10th section through the cortical lesion and every 5th section through the dorsal lateral geniculate nucleus were saved, mounted, and later stained with cresyl violet. Thereafter, conventional methods were followed for reconstruction of the lesions by examination for retrograde degeneration. Particular attention was paid to the possibility of survival of any principal cells in the dorsal lateral geniculate nucleus.

\section{RESULTS}

\section{Behavioral Results}

Preoperatively, rats trained on the rotated $\mathrm{HV}$ problem $(\mathrm{N}=11)$ learned that problem in an average of $38.00 \pm 5.30$ mean $/ 32$ median trials to a criterion of 9 correct responses out of 10 consecutive trials. The rats trained on the rotated $\mathrm{OB}$ problem $(\mathrm{N}=11)$ learned that problem in an average of $23.91 \pm$ 2.48 mean $/ 23$ median trials to criterion. The difference is statistically significant $(t=2.41$, $d f=20$, $p<.05$ ). Thus, the mirror image problem is significantly more difficult to perform than the rotated OB problem, which has its stripes horizontally and vertically arranged.

After the subjects had recovered from their firststage ablations of the posterior neocortex, the rats trained on the rotated $\mathrm{HV}$ problem $(\mathrm{N}=10)$ relearned that problem in $22.70 \pm 3.36$ mean $/ 27$ median trials to criterion, and the rats retrained on the rotated $\mathrm{OB}$ problem $(\mathrm{N}=11)$ relearned in 13.55 \pm 5.42 mean $/ 8$ median trials to criterion. The difference is not significant $(\mathrm{t}=1.40, \mathrm{df}=19)$. The direction of the interoperative performances, however, suggests that the mirror-image problem is more difficult.

Following the second-stage ablation of the remaining posterior cortex, the rats trained on the rotated $\mathrm{HV}$ problem $(\mathrm{N}=9)$ performed at a level of $83.44 \pm 5.25 \%$ mean $/ 89 \%$ median correct responses in the last 100 trials of final relearning. Rats trained on the rotated OB problem $(\mathrm{N}=9)$, however, performed at chance level $(50.56 \pm 1.94 \%$ mean $/ 51 \%$ median correct responses) during that same last 100 trials of final relearning. A two-factor analysis of variance with repeated measures on one factor showed a significant problem effect $(F=$ 48.75, df $=1,16, p<.001)$, trials effect $(F=8.70$, $\mathrm{df}=11,176, \mathrm{p}<.001)$, and Problem by Trials interaction $(F=3.70, \mathrm{df}=11,176, \mathrm{p}<.01)$.

Figure 1 compares the performances of rats trained on the original $\mathrm{HV}$ and $\mathrm{OB}$ problems from the data of Lavond et al. (1978) (Figure 1A) with those of rats trained on the rotated $\mathrm{HV}$ and $\mathrm{OB}$ problems

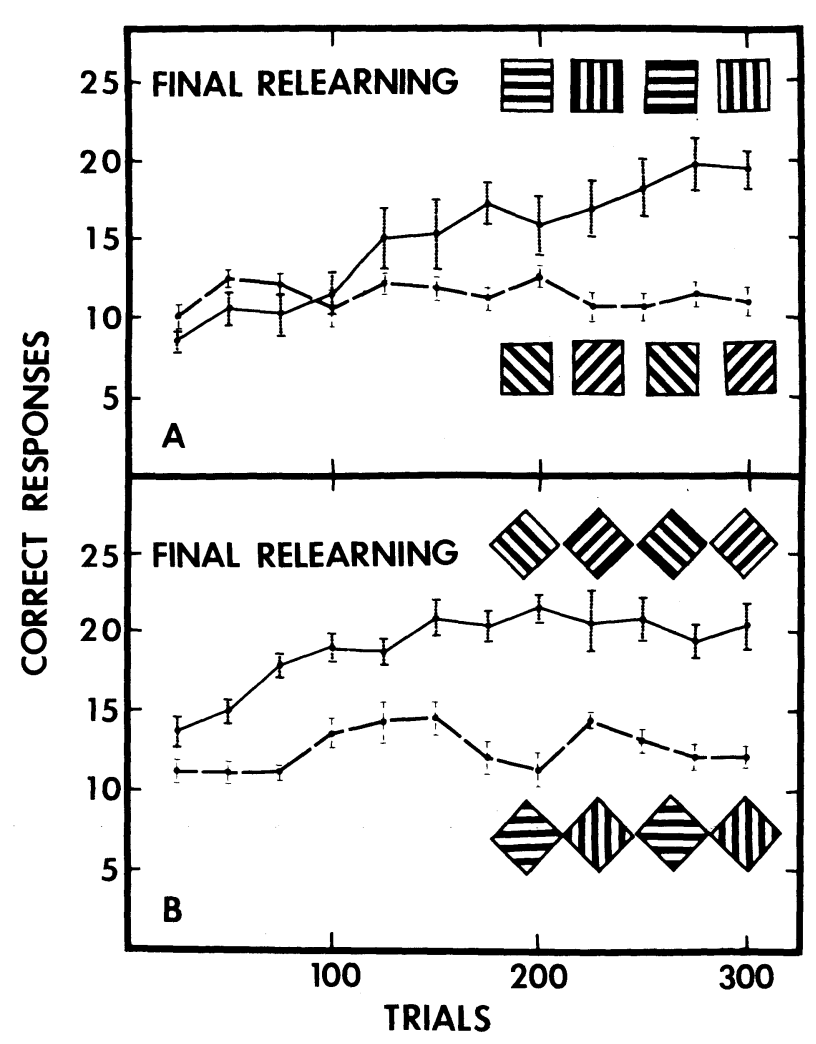

Figure 1. Comparison of the correct responses in blocks of 25 trials for final relearning of the pattern problems. (A) Adapted from Lavond et al. (1978). (B) The rotated problems of the present study. 
from the present experiment (Figure 1B). The figures show that the mirror-image factor does not determine whether a problem can be relearned ultimately by visually decorticated rats. In fact, a comparison of the performances of the rotated $\mathrm{HV}$ and $\mathrm{OB}$ groups for the first 12 trials and the last 12 trials on the first day of final retraining showed that the rotated OB group did not improve $(t=1.41$, $\mathrm{df}=16$ ) while the rats trained on the rotated $\mathrm{HV}$ problem did improve $(\mathrm{t}=2.35, \mathrm{df}=16, \mathrm{p}<.05)$. The rate of recovery of the rotated $\mathrm{HV}$ problem (Figure 1B) is far more substantial than the rate of recovery of the original $\mathrm{HV}$ problem reported by Lavond et al. (Figure 1A).

Finally, all of the rats in the present study were trained on a black-white discrimination following the final relearning trials of the pattern problems. Rats trained on the rotated $\mathrm{HV}$ problem $(\mathrm{N}=9)$ learned the black-white problem in $11.56 \pm 4.90$ mean $/ 6$ median trials to a $9 / 10$ criterion. Rats trained on the rotated OB problem $(N=9)$ learned the blackwhite problem in $5.67 \pm 1.98$ mean $/ 4$ median trials. The difference is nonsignificant $(t=1.11$, $\mathrm{df}=16)$. Thus, both groups of rats learned the black-white problem equally well regardless of their performance on the pattern problem.

\section{Histological Results}

Figure 2 presents the reconstructions of the brains of all of the subjects. Each of the diagrams presents an estimate of the surface extent of the cortical ablation and sections through the left and right dorsal lateral geniculate nuclei in which the degenerated regions are depicted in black. Adjacent to the diagrams are scores which give the number of trials each rat required for preoperative learning of its problem and the animal's percent correct responses during the final 100 retraining trials on its problem $\left(R_{2}\right)$. The data indicate that the differences between the two groups' ultimate postoperative performances were not due to intergroup differences between the extent of the cortical ablations, and also that all except three of the subjects had sustained ablations that were large enough to bring about the complete retrograde degeneration of the dorsal lateral geniculate nuclei. Of the three rats with unilateral dorsal lateral geniculate sparing of cells, two rats were in the rotated $\mathrm{HV}$ group and one rat was in the rotated OB group.

\section{DISCUSSION}

Lavond et al. (1978) correctly concluded that visual form perception is a function of the visual cortex. In their experiment, they compared groups of rats trained on either the $\mathrm{HV}$ problem or the OB problem and subjected to serial posterior decortications with

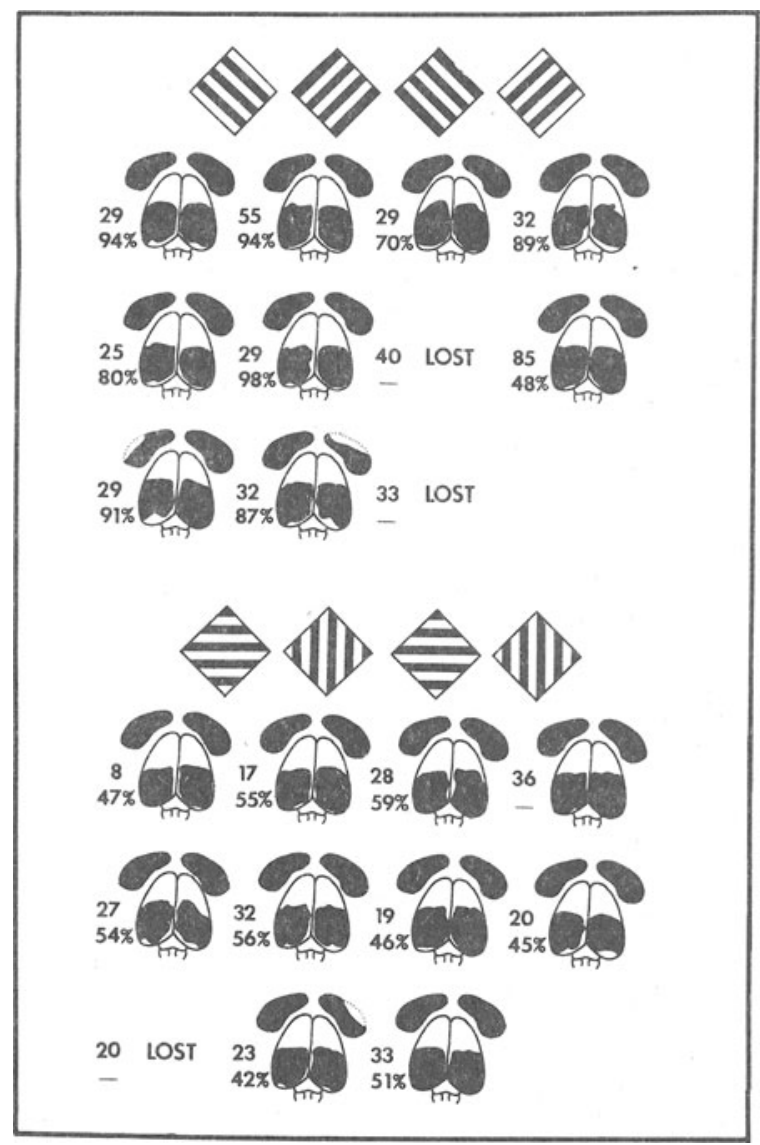

Figure 2. Surface diagrams of radical cortical ablations and representations of degeneration in the respective dorsal lateral geniculate nuclei. The top number next to each figure is the number of trials taken to learn the task, and the bottom number is the percentage of correct responses during the final 100 trials of final relearning.

interoperative retraining and extensive final retraining. They reported that posteriorly decorticated rats easily relearned the HV problem. However, similarly treated rats could not relearn the OB problem. In fact, animals with incomplete lesions of the posterior visual cortex, as assessed by sparing of cells in the dorsal lateral geniculate nuclei, were incapable of solving the OB problem when they had the same advantages of serial lesions, interoperative retraining, and extensive final retraining. Lavond et al. attributed the difference in the rats' performance on the two problems to the differences in local flux and local contour cues between the HV and OB problems. Thus, the HV problem can be solved by animals that consistently examine the same edge of the horizontally and vertically striped doors. If the rat examines only the bottom edges, for example, then the horizontally striped door will always have a solid white or black stripe at the bottom whereas the vertically striped door will always have the bottom 
edge broken by a series of black and white stripes. In the OB problem, all edges are broken by black and white stripes and therefore the OB problem cannot be solved by use of differential local flux or local contour cues. As a result, Lavond et al. concluded that the HV problem is not a true test of form perception because it does not meet the criteria outlined by Ritchie et al. (1976). According to those criteria, a test of form perception must be equated for overall flux, overall contour, local flux, and local contour (Dalby, Meyer, \& Meyer, 1970; Doty, 1971; Pavlov, 1927; Ritchie et al., 1976).

The Lavond et al. (1978) study could be criticized because the $\mathrm{OB}$ problem is a mirror-image problem, and it was found to be more difficult for rats to initially learn the OB problem than it was to learn the HV problem, which was easily learned in the same number of trials as it takes to learn a simple black-white discrimination (cf. Spear \& Barbas, 1975; Spear \& Braun, 1969a). Thus, the OB problem may be impossible for decorticated animals to learn because of its unusual characteristics rather than because it is a better test of form perception. The present experiment tested this conjecture by rotating the original $\mathrm{HV}$ and $\mathrm{OB}$ stimuli by $45 \mathrm{deg}$. The rotated $\mathrm{HV}$ problem became a mirror-image problem and was found to be more difficult for normal rats to learn than the rotated OB problem, which now was as easily learned as a black-white discrimination. The rats were subjected to the same serial lesion procedure with interoperative retraining and final relearning as in the experiment by Lavond et al. Contrary to the criticisms, it was found that posteriorly decorticated rats easily solved the rotated $\mathrm{HV}$ problem, which was the mirror-image and more difficult task. The other group of posteriorly decorticated rats found it impossible to relearn the rotated OB problem although the orientations of the stripes were horizontally and vertically arranged. Thus, the rotated OB problem was not relearned despite the fact that the problem was easily learned. Decorticated rats can relearn the HV problem, no matter what the orientation of the stripes, but they cannot relearn the OB problem in either of its two orientations (Lavond et al.; present experiment). The present experiment further substantiates the conclusion of Lavond et al. that the HV problem can be solved on the basis of local cues, and that the OB problem has to be solved solely on the basis of the orientations of the lines.

The fact that the HV problem is defective as a measure of visual form perception (Lavond et al., 1978; present experiment) poses a serious problem concerning the appropriateness of the conclusions of a number of recent neurobehavioral experiments that have challenged Lashley's theory (1939) of the cortical dependence of form perception. The HV problem is relearned by decorticated rats (Spear \&
Barbas, 1975), cats (Baumann \& Spear, 1977; Spear \& Braun, 1969b), and tree shrews (Killackey, Snyder, \& Diamond, 1971). The discrepancy between these experiments in which it is claimed that form perception survives cortical lesions and those experiments that report that decorticated animals are incapable of form discriminations (e.g., Horel et al., 1966; Jonason et al., 1970) typically has been attributed to differences in paradigm (one-stage or serial lesions; interoperative retraining; extensive retraining) and lesion size (complete or incomplete). However, Lavond et al. clearly have shown that differences in paradigm and lesion size do not account for the differences in performances on the $\mathrm{HV}$ and $\mathrm{OB}$ problems. Thus, rats subjected to serial ablations with interoperative retraining and extensive final relearning, as in the experiment by Spear and Barbas, easily relearned the HV problem but could not relearn the OB problem. Furthermore, similarly treated rats with cortical lesions restricted to areas 17-18-18a, instead of the radical posterior decortications used by Horel et al., for example, could not solve the $\mathrm{OB}$ problem although there was considerable sparing of principal cells in the dorsal lateral geniculate nuclei. The difference in outcomes is due to a fundamental difference between the $\mathrm{HV}$ and $\mathrm{OB}$ problems. The HV problem is not a good test of form perception because potentially it can be solved by local flux and local contour cues. The OB problem is a better test of form perception because it meets the criteria for tests of form perception emphasized by Ritchie et al. (1976).

The HV problem is not the only widely accepted test of form perception. Lashley (1938) himself used a battery of tests that includes nearly every discrimination problem that since has been used to evaluate residual form perception. A number of investigators follow the strategy of using batteries of tests to evaluate form perception, and it might be questioned whether the results for the original and rotated $O B$ problems suffice to allow the conclusion that decorticated animals are form blind. Thus, in this conception, arrays of stripes as presented in the $\mathrm{HV}$ and $\mathrm{OB}$ problems can be considered to be tests of pattern perception rather than tests of form perception, with the latter defined as the capacity to form discriminations between pairs of isolated figures.

However, the very great majority of form-perception tests consist of stimuli that contain local flux and local contour cues, and thus potentially can be solved by animals with posterior decortications. In fact, every one of the tests used by Lashley (1939) when he concluded that form perception was a function of the visual cortex potentially can be solved by rats who learn to respond to only that part of the display that they touch when making a choice, an effect that is described as stimulus-response spatial contiguity (Meyer, Treichler, \& Meyer, 1965). Thus, 
animals tend to respond to parts of stimuli rather than to the whole stimulus configuration.

The upright vs. inverted triangles problem is a good example of a task that is commonly used to assess form discrimination but in which the stimulusresponse spatial contiguity effect renders the problem solvable in terms of local flux and local contour cues. If the triangular forms are displayed upon doors that are hinged at the tops, then the animals will respond by pushing the doors open at the bottom edges where there is better leverage. Under such conditions, the animal will look at the base of the upright triangle and at the apex of the inverted triangle. As a result, the local flux and local contour at the bottom of the upright triangle is very much greater than that of the inverted triangle, even though the overall flux and contour for the stimuli may have been carefully equated. As Winans (1967, 1971) has shown, the triangles problem can be solved by cats with visual cortical ablations, but only if the triangles are large enough so that some components of the stimuli are close to the bottom edges of the stimulus displays. Thus, it is not surprising that tree shrews with large posterior injuries also can solve the triangles problem (Killackey et al., 1971). Like Winan's cats, posteriorly decorticated tree shrews can use local flux and local contour cues.

In a variation of the triangles problem, Killackey et al. (1971) presented posteriorly decorticated tree shrews with upright and inverted triangles that were embedded in surrounding annuli. The annuli reduced the saliency of the local flux and local contour cues and the tree shrew found the problem to be much more difficult to learn than the usual triangles problem. The animal did learn the problem, however, probably because the stimulus-response spatial contiguity helped the tree shrew to find those subtle differences in local cues. Killackey et al. used another method of training two tree shrews that seems to have helped the shrews to find the local flux and local contour cues. Thus, after it was found that reduction of the size of the triangles within the annuli did not help the animals to solve the problem, Killackey et al. placed half-circles above the normalsized triangles and trained the shrews to criterion on that problem. The bottom edges of the triangles thus were free of the circle, and the problem was easily learned. Next, the half-circles were moved to the bottom edges of the triangles and the base-down triangle with half-circle was positioned more closely to the bottom edge of the stimulus display than the apex-down triangle with half-circle. The problem was learned faster than when the half-circles were at the tops of the figures and when those figures were centered on the stimulus displays. Finally, the full circles again were added to the original triangles problem and the posteriorly decorticated tree shrews very easily relearned the problem. Thus, by a process of successive problems Killackey et al. may have inadvertently trained their posteriorly decorticated tree shrews to locate the subtle local flux and local contour cues that allowed the animals to easily solve the embedded triangles problem.

Unlike any of the triangles problems, the $\mathrm{OB}$ pattern problem has the advantage that it does not matter where the animals look, at small or large or peculiar subsectors, because the $\mathrm{OB}$ problem controls for the sampling bias of stimulus-response spatial contiguity. However, the sampling bias for tests of form perception can be controlled in other ways. Lashley (1939) himself minimized the contiguity effect by limiting the number of trials that a rat had in order to solve any particular problem to about 100 trials. This procedure thus limited the opportunity that the animals had for discovering and making use of the stimulus-response relations within each stimulus pair. As a result, Lashley correctly concluded that form perception is cortically dependent despite the deficiencies within the stimuli he used to evaluate form perception. Studies in which a large number of trials are necessary to achieve criterion should be held suspect for procedural (uncontrolled stimulus-response contiguity) and for statistical reasons (the greater the number of trials, the better the possibility of achieving a particular criterion level by chance).

Another method is to alter the positions of the forms within the stimulus displays on a trial-to-trial basis. Thus, the animals cannot use the frame of the stimulus to find consistent differences in the local cues of the stimulus forms. This method has been used in experiments with cats by Doty (1971) and by Sprague, Levy, DiBerardino, and Berlucchi (1977). In those experiments, the isolated forms were discriminated by cats with bilateral striate ablations, but were not discriminated by cats with ablations that included the .parallel cortical projection of the tectopulvinar visual system. The conclusions of the latter experimenters are among the few that agree with Lashley (1939) that visual form perception is cortically dependent.

Inasmuch as better controlled experiments, such as those of Doty (1971), Lashley (1939), and Sprague et al. (1977), yield the same results as experiments in which either the original or rotated $O B$ problems have been used, there is no reason to believe that there is any special merit to the use of batteries of tests in assessments of residual form perception. Thus, batteries of tests of form perception are only as good as the individual tests. As a result, findings based upon the use of the OB problems are generalizable to any other test of form perception that adequately controls for solutions in terms of differential flux and contour cues. 
It might still be argued, however, that the $O B$ problems are not adequate tests of form perception if it is believed that decorticated animals are capable of detecting orientations, but that the acuity of the stripes used by Horel et al. (1966), Jonason et al. (1970), Lavond et al. (1978), and the present experimenters cannot be discriminated by posteriorly decorticated animals. Dean (1978), Lashley (1931), and Wiesenfeld and Branchek (1976), all found that decorticated rats could solve problems with an acuity of .5 cycle/deg but not of 1.0 cycle $/ \mathrm{deg}$. However, each rat in the Thompson-Bryant (1955) apparatus used by Lavond et al., for example, had the choice of several degrees of acuity between the start compartment and the barrier that separated the stimulus doors, from .33 to .05 cycle/deg, in which to make his decision. Thus, the animals that have been tested on the OB problems were presented with stimuli that were well within the range of acuity for posteriorly decorticated rats.

In addition to residual acuity, decorticated animals have a number of other residual capacities. Pavlov (1927), for example, typically found recovery of conditioned responses to visual stimuli. Kluver (1941) reported a number of visual tasks that monkeys without visual cortex were able to solve. Posteriorly decorticated animals can respond to moving perimetric stimuli (Kirvel, Greenfield, \& Meyer, 1974); can respond to optokinetic stimuli (Smith, 1937; Wood, Spear, \& Braun, 1973); may be able to respond to depth cues (Braun, Lundy, \& McCarthy, 1970; Meyer, 1963; Meyer, Anderson, \& Braun, 1966); can visually place when injected with amphetamine (Braun, 1966; Meyer, Horel, \& Meyer, 1963; Ritchie et al., 1976); can accurately estimate distance in a jumping stand (Lashley, 1930); can discriminate between representative perspectives of near and distant stimuli (Wetzel, 1969); can discriminate between flux-equated check patterns of varying degrees of coarseness (Dalby et al., 1970); can discriminate between flux-equated arrays of varying sizes of disks (Dalby et al., 1970); can discriminate between black and white doors (Glendenning, 1972; Horel et al., 1966; Lashley, 1935; Thompson, 1960; cf. review by Meyer \& Meyer, 1977); and seem to be able to discriminate between the local flux and local contour cues in the horizontal vs. vertical stripes problem (Baumann \& Spear, 1977; Dru, Walker, \& Walker, 1975a, 1975b; Lavond et al., 1978; Spear \& Barbas, 1975; Spear \& Braun, 1969b). The problem of assessing form perception is particularly acute when these numerous residual capacities have not been taken into account.

When residual visual capacities have been properly accounted for, then, posteriorly decorticated animals cannot discriminate the orientations of edges. This ability is the minimum requirement for form perception in the feature-detector theory (Hubel \&
Wiesel, 1959, 1962, 1965) and in the spatial frequency theory (Cavanagh, 1978; Maffei \& Fiorentini, 1973). This result is robust enough to overcome the effects of mirror image, obliqueness of lines, and the relative difficulties of tasks when rigorous and sophisticated controls have been used for detecting visual capacities. Thus, the conclusion of Lashley (1939) still stands: Visual form perception is a function of the visual cortex.

\section{REFERENCES}

Baumann, T. P., \& Spear, P. D. Evidence for recovery of spatial pattern vision by cats with visual cortex damage. Experimental Neurology, 1977, 57, 603-612.

Braun, J. J. The neocortex and visual placing in rats. Brain Research, 1966, 1, 381-394.

Braun, J. J., Lundy, E. G., \& McCarthy, F. V. Depth discrimination in rats following removal of visual neocortex. Brain Research, 1970, 20, 283-291.

Cavanagh, P. Size and position invariance in the visual system. Perception, 1978, 7, 167-177.

DEAN, P. Visual acuity in hooded rats: Effects of superior collicular or posterior neocortical lesions. Brain Research, 1978, 156, 17-31.

Dalby, D. A., Meyer, D. R., \& Meyer, P. M. Effects of occipital neocortical lesions upon visual discriminations in the cat. Physiology \& Behavior, 1970, 5, 727-734.

Doty, R. W. Survival of pattern vision after removal of striate cortex in the cat. Journal of Comparative Neurology, 1971, 143, 341-369.

Dru, D.,. Walker, J. P., \& Walker, J. B. Self-produced locomotion restores visual capacity after striate lesions. Science, 1975, 187, 265-266. (a)

Dru, D., Walker, J. B., \& Walker, J. P. Recovery of pattern vision following serial lesions of striate cortex. Brain Research, 1975, 88, 353-356. (b)

Gelle Rman, L. W. Chance orders of alternating stimuli in visual discrimination experiments. Journal of Genetic Psychology, 1933, 42, 207-208.

GLendenning, R. L. Effects of training between two unilateral lesions of visual cortex upon ultimate retention of black-white habits by rats. Journal of Comparative and Physiological Psychology, 1972, 80, 216-229.

Horel, J. A., Bettinger, L. A., Royce, G. J., \& Meyer, D. R. Role of neocortex in the learning of two visual habits by the rat. Journal of Comparative and Physiological Psychology, 1966, 61, 66-78.

Hubel, D. H., \& Wiesel, T. N. Receptive fields of single neurones in the cat's striate cortex. Journal of Physiology, $1959,148,574-591$.

Hubel, D. H., \& Wiesel, T. N. Receptive fields, binocular interaction and functional architecture in the cat's visual cortex. Journal of Physiology, 1962, 160, 106-154.

Hubel, D. H., \& Wiesel, T. N. Receptive fields and functional architecture in two nonstriate visual areas (18 and 19) of the cat. Journal of Neurophysiology, 1965, 28, 229-289.

Hughes, H. C. Anatomical and neurobehavioral investigations concerning the thalamocortical organization of the rat's visual system. Journal of Comparative Neurology, 1977, 175, 311-335.

Jonason, K. R., Lauber, S., Robbins, M. J., Meyer, P. M. \& MEYER, D. R. The effects of dl-amphetamine upon discrimination performance. Journal of Comparative and Physiological Psychology, 1970, 73, 47-55.

Killackey, H., Snyder, M., \& Diamond, I. T. Function of striate and temporal cortex in the tree shrew. Journal of Comparative and Physiological Psychology, 1971, 171, 1-29.

Kirvel, R. D., Greenfield, R. A., \& Meyer, D. R. Multimodal sensory neglect in rats with radical unilateral posterior 
isocortical and superior collicular ablations. Journal of Comparative and Physiological Psychology, 1974, 87, 156-162.

KLUVER, H. Visual functions after removal of the occipital lobes. Journal of Psychology, 1941, 11, 23-45.

KriEg, W. J. S. Connections of the cerebral cortex. A: Topography of the cortical area; B: Structure of the cortical area. Journal of Comparative Neurology, 1946, 84, 221-323.

LASHLEY, K. S. The mechanism of vision. I. A method for rapid analysis of pattern-vision in the rat. Journal of Genetic Psychology, 1930, 37, 453-460.

LASHLEY, K. S. The mechanism of vision. IV. The cerebral areas necessary for pattern vision in the rat. Journal of Comparative Neurology, 1931, 53, 419-478.

LAShley, K. S. The mechanism of vision. XII. Nervous structures concerned in the acquisition and retention of habits based on reactions to light. Comparative Psychological Monographs, 1935, 11, 43-79.

LAShley, K. S. The mechanism of vision. XV. Preliminary studies of the rat's capacity for detail vision. Journal of General Psychology, 1938, 18, 123-193.

LASHLEY, K. S. The mechanism of vision. XVI. The functioning of small remnants of the visual cortex. Journal of Comparative Neurology, 1939, 70, 45-67.

Lavond, D. G., Hata, M. G., Gray, T. S., Geckler, C. L., MEYER, P. M., \& MEYER, D. R. Visual form perception is a function of the visual cortex. Physiological Psychology, 1978, 6, 471-477.

Maffei, L., \& Fiorentini, A. The visual cortex as a spatial frequency analyser. Vision Research, 1973, 13, 1255-1268.

Meyer, P. M. Analysis of visual behavior in cats with extensive neocortical ablations. Journal of Comparative and Physiological Psychology, 1963, 56, 397-401.

Meyer, P. M., Anderson, R. A., \& Braun, J. J. Visual cliff preferences of the visual cortex in cats and rats. Psychonomic Science, 1966, 4, 269-270.

Meyer, P. M., Horel, J. A., \& Meyer, D. R. Effects of dl-amphetamine upon placing responses in neodecorticate cats. Journal of Comparative and Physiological Psychology, 1963, 56, 402-404.

Meyer, P. M., \& Meyer, D. R. Neurosurgical procedures with special reference to aspiration lesions. In R. A. Meyers (Ed.), Methods in neuropsychology. New York: Academic Press, 1971.

Meyer, D. R., \& Meyer, P. M. Dynamics and bases of recoveries of functions after injuries to the cerebral cortex. Physiological Psychology, 1977, 5, 133-165.

Meyer, D. R., Treichler, F. R., \& Meyer, P. M. Discretetrial training techniques and stimulus variables. In A. M.
Schrier, H. F. Harlow, and F. Stollnitz (Eds.), Behavior of nonhuman primates. New York: Academic Press, 1965.

Pavlov, I. P. Conditioned reflexes. London: Oxford University Press, 1927.

Ritchie, G. D., Meyer, P. M., \& Meyer, D. R. The residual spatial vision of cats with lesions of the visual cortex. Experimental Neurology, 1976, 53, 227-253.

Sмiтh, K. U. The postoperative effect of removal of the striate cortex upon certain unlearned visually controlled reactions in the cat. Journal of Genetic Psychology, 1937, 50, 137-156.

Spear, P. D., \& Barbas, H. Recovery of pattern discrimination ability in rats receiving serial or one-stage visual cortex lesions. Brain Research, 1975, 94, 337-346.

Spear, P. D., \& Braun, J. J. Nonequivalence of normal and posteriorly neodecorticated rats on two brightness discrimination problems. Journal of Comparative and Physiological Psychology, 1969, 67, 235-239. (a)

Spear, P. D., \& Braun, J. J. Pattern discrimination following removal of visual neocortex in the cat. Experimental Neurology, 1969, 24, 331-348. (b)

Sprague, J. M., Levy, J., Diberardino, A., \& Berlucchi, G. Visual cortical areas mediating form discrimination in the cat. Journal of Comparative Neurology, 1977, 172, 441-488.

Tном PSon, R. Retention of a brightness discrimination following neocortical damage in the rat. Journal of Comparative and Physiological Psychology, 1960, 53, 212-215.

Thompson, R., \& BRYANT, J. H. Memory as affected by activity of the relevant receptor. Psychological Reports, 1955, 13, 393-400.

Wiesenfeld, Z., \& BrancheK, T. Refractive state and visual acuity in the hooded rat. Vision Research, 1976, 16, 823-827.

Wetzel, A. B. Visual cortical lesions in the cat: A study of depth and pattern discrimination. Journal of Comparative and Physiological Psychology, 1969, 3, 580-588.

Winans, S. Visual form discrimination after removal of the visual cortex in cats. Science, 1967, 158, 944-946.

Winans, S. Visual cues used by normal and visual decorticate cats to discriminate figures of equal luminous flux. Journal of Comparative and Physiological Psychology, 1971, 74, 167-178.

Wood, C. C., Spear, P. D., \& Braun, J. J. Direction-specific deficits in horizontal optokinetic nystagmus following removal of visual cortex in the cat. Brain Research, 1973, 60, 231-237.

(Received for publication September 13, 1979; revision accepted October 23, 1979.) 